\title{
Extracorporeal membrane oxygenation in respiratory failure for pulmonary contusion and bronchial disruption after trauma
}

\author{
Andrea Campione, MD, ${ }^{a}$ Marco Agostini, MD, ${ }^{\mathrm{b}}$ Mario Portolan, MD, ${ }^{\mathrm{c}}$ Antonella Alloisio, MD, ${ }^{\mathrm{a}}$ Carlo Fino, MD, \\ and Giuseppe Vassallo, MD, ${ }^{\text {a }}$ Cuneo, Italy
}

$\mathrm{E}$ xtracorporeal membrane oxygenation (ECMO) may offer lifesaving treatment in severe pulmonary contusion or acute respiratory distress syndrome when conventional treatments have failed. ${ }^{1,2}$

Although ECMO has become the standard treatment for neonatal severe respiratory failure, interest in adult ECMO weakened because of the high mortality until investigators ${ }^{3}$ began dictating that it should be used in children and in adult respiratory failure.

Use in trauma is restricted ${ }^{4,5}$ because of the risk of systemic anticoagulation in patients with multiple trauma.

\section{Clinical Summary}

A 14-year-old boy experienced a serious blunt thoracic trauma during a go-cart race.

On admission to the emergency department, he was awake and spontaneously breathing but dyspneic with hemoptysis and severe hypoxemia $\left(\mathrm{SAO}_{2}<50 \%\right)$. As soon as endotracheal ventilation was started, the gas exchange rapidly worsened with subcutaneous emphysema and cardiac arrest, which necessitated resuscitation and urgent chest drainage for the onset of a hypertensive right pneumothorax.

Oxygen saturation levels worsened, and continuous massive air leakage was present. A bronchoscopy was mandatory, but it failed to reveal injuries in the trachea and main stem bronchi. An endobronchial tube with left intubation was inserted (Robertshaw n.35), but the gas exchange did not improve dramatically. Emergency chest and abdomen computed tomography scans showed a suspicious lower right bronchial tear with bilateral pulmonary contusion, a large quantity of abdominal fluid, and a mild left pneumothorax. After another chest tube was inserted on the left, drainage on the left gas exchange remained stable with an $\mathrm{SAO}_{2}$ of $50 \%$.

A team of cardiothoracic surgeons and anesthesiologists recommended a venovenous ECMO, because they agreed that the boy would not survive.

Regardless of the trauma, the patient was placed on an extracorporeal circuit (Bio-Medicus; Medtronic Inc, Minneapolis,

From the Departments of General Thoracic Surgery, ${ }^{\mathrm{a}}$ Cardiac Surgery, ${ }^{\mathrm{b}}$ and Cardiovascular Anesthesia and Intensive Care, ${ }^{\mathrm{c}} \mathrm{Hospital}$ of Cuneo, Cuneo, Italy.

Received for publication Jan 17, 2007; accepted for publication Feb 17, 2007.

Address for reprints: Andrea Campione, MD, Hospital of Cuneo, General Thoracic Surgery, Via Michele Coppino 26, Cuneo 12100, Italy (E-mail: andikampione@yahoo.it).

J Thorac Cardiovasc Surg 2007;133:1673-4

$0022-5223 / \$ 32.00$

Copyright $\odot 2007$ by The American Association for Thoracic Surgery doi:10.1016/j.jtcvs.2007.02.011
Minn) with venous access achieved through the right jugular vein and right femoral vein using a percutaneous Seldinger technique.

Anticoagulation with intravenous heparin was set to activated clotting times between 250 and 300 seconds.

Heparinized blood was extracted from the internal jugular vein and through a centrifugal pump (Bio-Medicus; Medtronic Inc) reached a membrane oxygenator (Affinity, Avecor Cardiovascular, Plymouth, Minn) and heat exchanger (Biotherm; Medtronic Inc) and returned through the femoral vein.

With a blood flow of $2.5 \mathrm{~L} / \mathrm{min}$ and an $\mathrm{FIO}_{2}$ of $60 \%$, the oxygenation saturation increased and the patient maintained good oxygen levels averaging 95\%; thus, surgical intervention was possible.

An exploratory laparotomy showed a large amount of ascites without intraperitoneal or retroperitoneal visceral injury, and a right posterolateral thoracotomy confirmed the large pulmonary contusion with multiple parenchymal tears and a transverse disruption in the intermediate bronchus.

The location of the injury, size of the bronchial tree, and presence of irregular borders did not allow a conservative approach to bronchus without the risk of subtotal stenosis; therefore, a lower bilobectomy was performed.

Three days later, after a short period of coagulopathy that was treated with fresh-frozen plasma, the patient was successfully weaned from ECMO.

In the postoperative course, a tracheostomy was planned, and the patient was then successfully discharged from any kind of ventilatory support within 4 weeks and referred to a rehabilitation center. Two years after the accident, the boy is doing well.

\section{Discussion}

In trauma victims with possible intracranial and abdominal bleeding, and long bones and pelvic fractures, ECMO should be performed only as a last resort.

The successful outcome of this case is most likely attributable to the young age of the patient, early institution of ECMO, and aggressive surgical intervention after cardiopulmonary stabilization.

Ascites was probably associated with prolonged mesenteric hypoxemia.

\section{References}

1. Peek GJ, Moore HM, Moore N, Sosnowski AW, Firmin RK. Extracorporeal membrane oxygenation for adult respiratory failure. Chest. 1997; 112:759-64.

2. Zwischenberger JB, Conrad SA, Alpard SK, Grier LR, Bidani A. Percutaneous extracorporeal arteriovenous $\mathrm{CO} 2$ removal for severe respiratory failure. Ann Thorac Surg. 1999;68:181-7. 
3. Gattinoni L, Pesenti A, Mascheroni D, Marcolin R, Fumagalli R, Rossi F, et al. A low-frequency positive-pressure ventilation with extracorporeal $\mathrm{CO} 2$ removal in severe acute respiratory failure. JAMA. 1986;256:881-6.

4. Willms DC, Watchel TL, Daleiden AL, Dembitsky WP, Schibanoff JM, Gibbons JA. Venovenous extracorporeal life support in trau- matic bronchial disruption and adult respiratory distress syndrome using surface-heparinized equipment: case report. J Trauma. 1994; 2:252-4.

5. Michaels AJ, Schriener RJ, Kolla S, Awad SS, Rich PB, Reickert C, et al. Extracorporeal life support in pulmonary failure after trauma. J Trauma. 1999;4:638-45.

\title{
Reduction pneumoplasty for a giant right upper lobe bulla causing massive bilateral lung compression
}

\author{
Timothy L. Van Natta, MD, ${ }^{a}$ and Mark D. Iannettoni, MD, MBA, ${ }^{\mathrm{b}}$ Torrance, Calif and lowa City, la
}

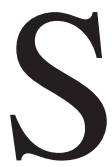

urgical therapy has been used for bullous emphysema since the mid-20th century. The best surgical candidates are often those with giant pulmonary bullae rather than those with diffuse disease. Several series describe selection criteria, techniques, and outcomes pertaining to the excision of giant bullae. ${ }^{1-3}$ In one report, the term "reduction pneumoplasty" was coined to denote giant bulla excision, and the accompanying review of 22 case series identified three harbingers of success. ${ }^{4}$ These involve the bulla size, degree of associated lung compression, and preoperative forced expiratory volume in 1 second $\left(\mathrm{FEV}_{1}\right)$. We present a patient with an enormous unilateral bulla compressing most of the right lung and much of the left lung. Bulla resection produced marked functional improvement and increased $\mathrm{FEV}_{1}$.

\section{Clinical Summary}

A 44-year-old foundry worker presented with progressive dyspnea and cough. Physical activity tolerance had deteriorated. Medical and family histories were unremarkable. He was exposed at work to airborne sand and metal dust. He regularly smoked marijuana and 2 to 3 daily cigarettes. Examination showed a chronically ill-appearing man with dyspnea on minimal exertion. Hyperresonant percussion notes were present over both hemithoraces, and breath sounds were diminished bilaterally. There were no stigmata of cor pulmonale. Chest radiograph was initially interpreted as showing large bilateral hydropneumothoraces (Figure 1), and he was referred to the University of Iowa Hospitals and Clinics for

\footnotetext{
From the Department of Surgery, Harbor-UCLA Medical Center, ${ }^{a}$ Torrance, Calif; and Department of Cardiothoracic Surgery, ${ }^{\mathrm{b}}$ University of Iowa, Iowa City, Ia.

Received for publication Jan 12, 2007; accepted for publication Feb 7, 2007.

Address for reprints: Timothy L. Van Natta, MD, Harbor-UCLA Medical Center, Department of Surgery, 1000 West Carson Street, Box 42, Torrance, CA 90509 (E-mail: timothy.vannatta@gmail.com).

J Thorac Cardiovasc Surg 2007;133:1674-5

$0022-5223 / \$ 32.00$

Copyright $\odot 2007$ by The American Association for Thoracic Surgery doi:10.1016/j.jtcvs.2007.02.010
}

treatment. Computed tomographic (CT) scan interpretation suggested bilateral giant bullous lung disease with air-fluid levels and extensive pulmonary compression (Figure 1). Alpha-1-antitrypsin level and complete blood count were normal. Forced vital capacity was $1.9 \mathrm{~L}$ and $\mathrm{FEV}_{1}$ was $1.4 \mathrm{~L}$, or $37 \%$ and $38 \%$ of predicted, respectively. Antibiotics and bronchodilators were prescribed. Given the patient's continued dyspnea, he was referred for surgical evaluation. Bullae resection through median sternotomy was advised.

Sternotomy was performed under general anesthesia, with a double-lumen endotracheal tube in place. A division of the anterior bulla wall occurred on sternal entry. Progressive left pulmonary reexpansion occurred, and that lung lacked overt emphysematous features. The bilateral seropurulent fluid was evacuated. Gram stain was negative. Isolated left pulmonary ventilation provided ample oxygenation, facilitating right lung evaluation and reduction pneumoplasty. A single, huge right upper lobe bulla had compressed the majority of the right lung and crossed beneath the sternum to produce marked compression of the left lung. This bulla had a narrow base, 3 to $4 \mathrm{~cm}$ diameter, off the apex. An Endo-GIA stapler with 3.5-mm staples (United States Surgical Corp, Norwalk, Conn) reinforced with Peri-Strips Dry (Synovis Surgical Innovations, St Paul, Minn) was used to excise the bulla and seal the underlying lung. A thin fibrinous rind around the right lung was easily excised. This produced good expansion of all lobes and obviated the need for right pleural tent creation. Thoracostomy tubes were placed, and the sternotomy was closed. Recovery was uneventful. Pleural fluid cultures were negative. Pathologic analysis indicated pleural inflammation and emphysema. At his second clinic follow-up 2.5 months later (Figure 2), the patient reported substantially improved exercise tolerance. Objectively, $\mathrm{FEV}_{1}$ improved from $1.4 \mathrm{~L}$ preoperatively to $3.5 \mathrm{~L}$ postoperatively (38\%-93\% of predicted, respectively).

\section{Discussion}

A comprehensive 1996 review of surgery for giant bullous emphysema concluded that three features portend success: bulla size exceeding one third of 1 hemithorax, marked compression of adjacent lung tissue (demonstrated by $\mathrm{CT}$ scan), and preoperative $\mathrm{FEV}_{1}$ less than $50 \%$ predicted. ${ }^{4}$ Our patient met all three criteria. Despite tremendous bilateral lung compression, the nonbullous 